\title{
Child sexual abuse presenting to District General Hospital, Chilaw
}

\author{
M D Chandrasiri ${ }^{1}$, D K Wijewardena ${ }^{2}$, S D Lanerolle ${ }^{1}$, S E Chandrasiri ${ }^{3}$, K P Wijewardena ${ }^{4}$, \\ R T Cooray ${ }^{5}$
}

(Index words: child sexual abuse, Sri Lanka, Chilaw, Northwestern)

\begin{abstract}
Introduction Incidence of child sexual abuse is increasing worldwide. There is little data on child sexual abuse in the North Western Province of Sri Lanka.

Objectives To describe the demographic and medico-legal findings of victims of sexual abuse aged less than 16 years and to identify factors associated with positive findings on medical-legal examination.
\end{abstract}

Methods This cross-sectional analytical study, analysed 132 victims, referred by authorities to General Hospital, Chilaw, from 2012 to 2014.

Results Mean age of the victims was 13.1years. Main types abuse were penetrative (61.4\%), intra-crural (39.4\%) and anal sex (10.6\%). The perpetrator was known in 94\%. Places of offence were offender's habitat (55.3\%), victim's home (23.5\%) and secluded areas (11.4\%). A positive history of penetrative sex (OR $=15.3 ; 95 \% \mathrm{Cl}$ 5.6-42), chronic sexual abuse (OR=4.8; $95 \% \mathrm{Cl} 2.2-10.5)$ and time lapse in reporting to authorities (OR=4.4; 95\% $\mathrm{Cl}$ 2.0-9.4) were significantly associated with presence of conclusive medical examinations findings. Children were less likely to be willing partners in intra-familial abuse compared to extra-familial abuse where the child was sometimes a willing partner, $(\mathrm{OR}=0.2 ; 95 \% \mathrm{Cl} 0.07-0.5)$. Adverse psychological outcomes were observed in $16.7 \%(n=22)$.

Conclusion Most children were victims of statutory rape and knew the perpetrator. In extra-familial abuse, child was sometimes a willing partner. A positive history of penetrative sex, number of abusive incidents and time lapse for presentation were important factors associated with conclusive medical findings.

Ceylon Medical Journal 2017; 62: 29-33

DOI: http://doi.org/10.4038/cmj.v62i1.8430

\section{Introduction}

Incidence of child sexual abuse (CSA) is increasing worldwide. Sri Lanka is no exception. Global prevalence of child sexual abuse varies from $7 \%$ to $38 \%$ [1,2]. A study in India in 2007, revealed that $53.2 \%$ of children were subjected to some form of CSA and most were under reported [3]. In Sri Lanka, the prevalence is unknown, and there is wide geographical variation. According to Sri Lanka Police, in 2015, 1654 child abuse cases were reported [4]. Police and National Child Protection Authority data is incomplete. Most incidents are underreported and data represent the tip of the iceberg. A study done in 2002, analyzed cases reported in three tertiary care centers representing North Central, Central and Western provinces [5]. There is no data regarding the North Western Province.

According to Sri Lankan law, person less than 18 years is considered as a child and the legal age for consent for sex is 16 years. Child sexual abuse is defined as, involvement of dependent, developmentally immature children and adolescents in sexual activities that they do not truly understand, to which they cannot give informed consent, which violate accepted social norms/ family roles, which are against the law [6]. CSA can be divided in to two categories; contact abuse such as physical contact with the child's genitals, breasts, mouth or actual sexual act with a child, and non-contact abuse such as indecent exposure, viewing child's genitalia, child pornography (enacting/ watching) and child prostitution [6].

Many issues complicate investigation of CSA cases. Medico-legal findings vary depending on professional experience, time of presentation, variations in ano-genital anatomy and pubertal status [7]. Positive physical findings are rare in many victims of CSA. According to literature, a positive history remains the single most important evidence in medico-legal proceedings [7]. The relationship between the age, ano-genital signs and nature

${ }^{1}$ Obstetrics and Gynaecology Unit and ${ }^{2}$ Judicial Medicine Unit, District General Hospital, Chilaw, ${ }^{3}$ Paediatrics Unit, Lady Ridgeway Children's Hospital, ${ }^{4}$ National Hospital of Sri Lanka and Peripheral Unit, Madampe, Sri Lanka.

Correspondence: MDC, e-mail: <manojdc1980329@gmail.com>. Received 26 August 2016 and revised version accepted 14 December 2016.

This is an open-access article distributed under the terms of the Creative Commons Attribution License, which permits unrestricted use, distribution, and reproduction in any medium, provided the original author and source are credited. 
of penetrating object is unclear. Studies which differentiate normal from abnormal ano-genital findings, which are suggestive of sexual abuse, are few. They are difficult to conduct due to ethical reasons. The authors have encountered frequent cases of CSA in this geographical area and it is important to ascertain if the demographics and other identified risk factors reported in the literature are prevalent in this areas too. Therefore, a descriptive study was done to describe the assailants, assault characteristics, medico-legal findings, adverse outcomes and to identify risk factors in alleged sexual abuse victims of less than 16 years of age.

\section{Methods}

A descriptive analytical study was done based on records from a medico-legal database. This included all children less than 16 years of age, referred by Police and Department of Probation, with alleged sexual abuse, to District General Hospital Chilaw during a period of two years from August 2012 to August 2014. This hospital is in the North-Western Province of Sri Lanka and at the time of the study was the only specialist referral center for judicial work in the Puttalam district. Referrals were made from the entire Puttalam district and part of the Kurunegala district, which covers a major part of the North Western Province. Approval was granted by the Ethical Review Committee of the Colombo South Teaching Hospital.

During the initial medico-legal examination, subjects underwent a structured interview and detailed physical examination. Pregnancy screening, sexually transmitted infections (STI) screening and psychiatric referrals were done in all. Findings of physical examination and genital examination were documented on body sketches. These examination findings were made by a single Consultant in Judicial Medicine. These retrospective data were extracted using a data sheet. For each case, demographic details of the victim, assailants, time lapse in reporting, medico-legal examination findings, STI and psychological disorders were recorded.

CSA was defined as mentioned in the introduction. Genital examination findings consistent with vaginal penetration were, distortion of hymen with deep clefts and tears, local absence of postero-lateral hymenal tissue and scarring of the posterior vestibulum and posterior fourchette. Findings consistent with anal penetration were, a combination of extensive perianal scarring and positive anal dilatation reflex test. The assailant was considered a stranger if the victim encountered that person for the first time on the day of incident. A previously acquainted person or any relatives were considered as a known person. The ano-genital findings were classified into two categories. Category 1: Specific findings supporting a history of penetrative abuse (vaginal/ anal) as mentioned above. Category 2: Normal appearing ano-genital area or non-specific findings, which does not exclude non-penetrative abuse but does not support vaginal/ anal penetration. The data was analysed by categorizing in to 'intra-familial' and 'extra-familial' abuse identify risk factors for abuse. Intra-familial abuse was defined as, abuse by a relative (e.g., father, stepfather, any other relative), and extra-familial abuse was defined as abuse by a stranger or a non-relative acquaintance of the victim. Although a child under 16 years cannot give consent legally, if the history revealed that the child had a consensual relationship with a person (e.g. boyfriend), it was classified as a 'willing partner' for analytical purpose. Logistic regression was done to identify associations with positive ano-genital findings and identify risk factors of intra-familial and extra-familial abuse.

\section{Results}

There were 132 victims of alleged CSA with ages ranging from 3 to 16 years, mean age was 13.1 years (SD $=2.8$ ) and median age was 13.9 years. Majority (77\%) were between ages 12 to 16 years. One hundred and twenty two (92.4\%) were females and 10 (7.6\%) were males; female: male ratio was 12:1. Fifty two (39\%) victims were from areas of Chilaw, Mundalama and Kuliyapitiya. Others were from rural areas of the North Western province.

All male victims $(n=10)$ were of pre-pubertal age. Among girls, 84 (68.9\%) had attained menarche at the time of the incident. Most common variation of the hymen was the fimbriated type ( $n=53 ; 43.4 \%)$. Other types were annular $(n=48 ; 39.3 \%)$ and tulip type $(n=11 ; 9 \%)$. Type of hymen was not recorded in $3(2.5 \%)$.

Thirty six (27.3\%) children had given up their education by the time or around the time of sexual abuse. Manual laboring ( $n=43 ; 36 \%)$ was the commonest employment among the victims' fathers. Of the families $58.3 \%$ had a single parent as a caregiver (Table 1).

Table 1. Description of victims' family background

\begin{tabular}{cc}
\hline Biological father & - Dead \\
Separated & $14(10.6 \%)$ \\
Biological mother - Dead & $26(19.7 \%)$ \\
Separated & $4(3 \%)$ \\
Mother working overseas & $10(7.6 \%)$ \\
\hline
\end{tabular}


Seventy nine (59.8\%) incidents were reported to authorities after a delay of more than seven days (mean= 40 days). Seventeen (12.9\%) children could not recall the exact date of the index incident. Alleged types of abuse according to the history given by the victim were, penetrating sex $(n=81 ; 61.4 \%$, ), digital penetration $(n=4 ; 3 \%$,), intra-crural sex $(n=52 ; 39.4 \%$, ), anal sex ( $n=14 ; 10.6 \%$,), physical battery $(n=15 ; 11.4 \%$,) and other libindous acts $(n=27 ; 20.5 \%)$. Two cases of attempted homicide and child prostitution were reported. The former was an attempt to forcefully ingest an organophosphate after sexual harassment by the perpetrator. One case of alcohol intoxication was also reported. Twelve denied of any incident. Majority of victims $n=83$, (62.9\%) were abused more than once, over a period of time. Mean time between incident and reporting to authorities was 40 days (IQR 3 - 45 days).

Place of alleged offence was at the offender's habitat either home or shop ( $n=73 ; 55.3 \%)$, child's own home ( $n=31 ; 23.5 \%)$ or secluded areas such as jungle, road or bathing areas $(n=15 ; 11.4 \%)$.

The alleged perpetrator was known to the victim in 94\% (Table 2). Fourteen (10.6\%) victims were abused by their caregiver. Age of the perpetrator was known in 58 (44\%) and the mean age was 28.5 years. (Range 11 - 65 years).
Table 2. Type of perpetrator

\begin{tabular}{lc}
\hline \multicolumn{2}{c}{ Perpetrator } \\
\hline Father/Step Father/ Grand Parent & $14(10.6 \%)$ \\
Other relative & $7(5.3 \%)$ \\
Boyfriend & $38(28.8 \%)$ \\
Known non-relative & $61(46.2 \%)$ \\
Stranger & $7(5.3 \%)$ \\
Several types of perpetrators & $5(3 \%)$ \\
Total & $132(100 \%)$ \\
\hline
\end{tabular}

Conclusive evidence of vaginal penetration was found in 78 (63.9\%) female victims, while anal penetration was found in 13 (9.8\%) victims.

Children were less likely to be willing partners in intra-familial abuse compared to extra-familial abuse, $(\mathrm{OR}=0.2$; 95\% CI 0.07-0.5). Less intra-familial abuse occured when the caregiver was the mother, but this was not statisticaly significant $(\mathrm{OR}=0.4$; 95\% CI 0.1-1.1 (Table 3).

Factors associated with positive medical evidence are shown in table 4 . A history of penetrative sex, chronic sexual abuse and delay in reporting to authorities were significantly associated with conclusive exami-nation findings. Willingness of the child, type of hymen and the pubertal status were not significantly associated.

Table 3. Characteristics of intra-familial and extra-familial abuse

\begin{tabular}{|c|c|c|c|c|}
\hline & $\begin{array}{l}\text { Intra-familial } \\
\text { abuse }(n=23)\end{array}$ & $\begin{array}{l}\text { Extra-familial } \\
\text { abuse }(n=109)\end{array}$ & Chi square & OR $(95 \%$ CI $)$ \\
\hline \multicolumn{5}{|l|}{ Pubertal status } \\
\hline Pre-pubertal & 11 & 36 & & \\
\hline Attained menarche & 12 & 73 & 1.8 & $1.8(0.7-4.6)$ \\
\hline \multicolumn{5}{|l|}{ History } \\
\hline Positive history & 19 & 81 & & \\
\hline Negative history & 4 & 28 & 0.7 & $1.6(0.5-5.2)$ \\
\hline \multicolumn{5}{|l|}{ No of incidents } \\
\hline Chronic abuse & 17 & 66 & & \\
\hline Single incident & 6 & 43 & 1.4 & $0.5(0.1-1.4)$ \\
\hline \multicolumn{5}{|l|}{ Willingness } \\
\hline Willing & 5 & 63 & & \\
\hline Unwilling & 18 & 46 & 9.8 & $0.2(0.07-0.5)$ \\
\hline \multicolumn{5}{|l|}{ Education } \\
\hline Not schooling & 6 & 30 & & \\
\hline Schooling & 17 & 79 & 0.02 & $1.07(0.3-2.9)$ \\
\hline \multicolumn{5}{|c|}{$\begin{array}{l}\text { Time lapse before reporting to } \\
\text { authorities }\end{array}$} \\
\hline Less than 7 days & 10 & 43 & & \\
\hline More than 7 days & 13 & 66 & 00.12 & $1.2(0.5-2.9)$ \\
\hline \multicolumn{5}{|l|}{ Care giver } \\
\hline Mother & 15 & 88 & 22.6 & $0.4(0.1-1.1)$ \\
\hline Other & 8 & 21 & & \\
\hline
\end{tabular}


Table 4. Factors associated with positive medical evidence of abuse

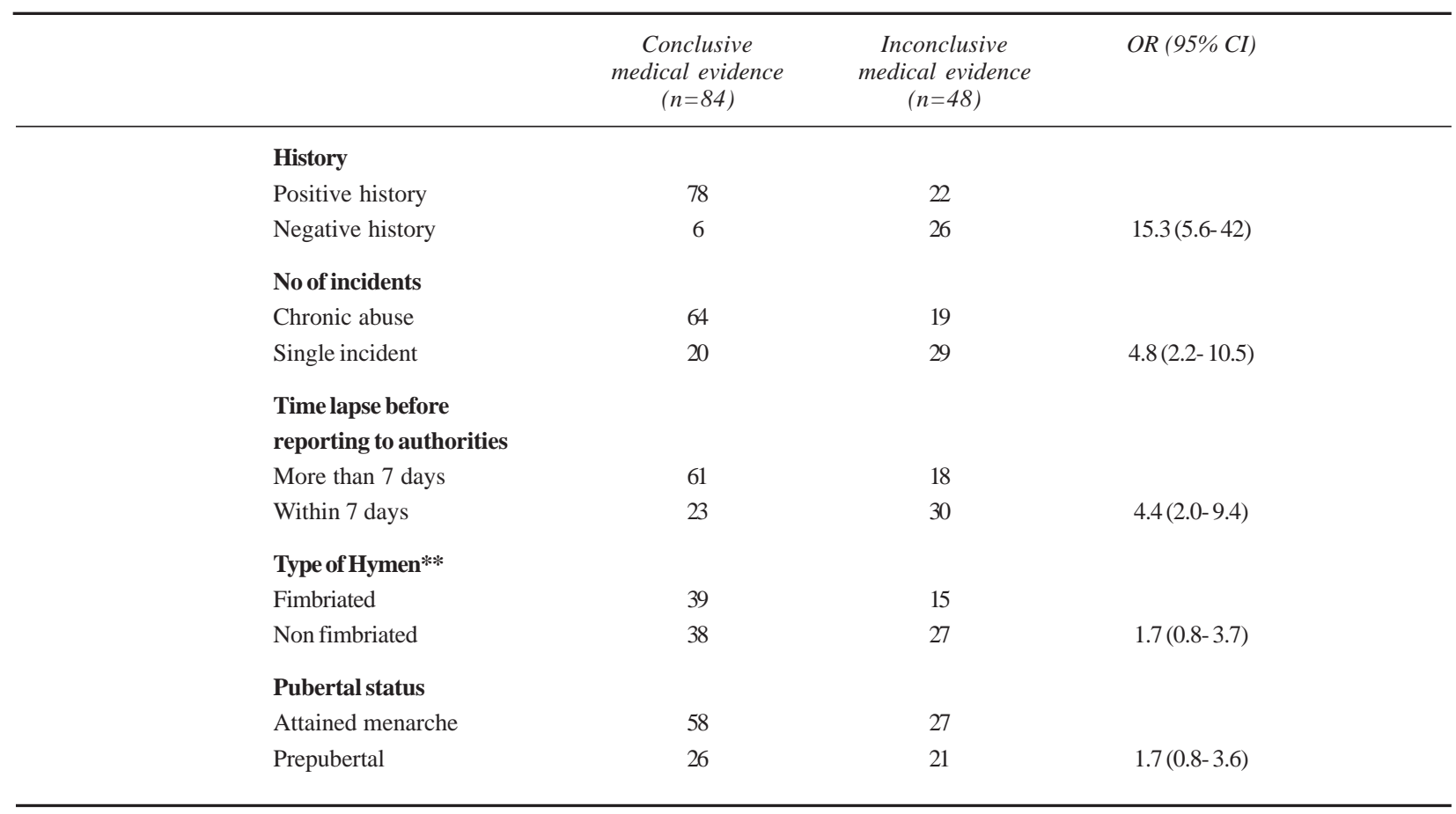

\section{Discussion}

A sizable number of vicitms were from Chilaw, Mundalama, and Kuliyapitiya areas. Majority of victims (77\%) were aged between 12 to 16 years, which is consistent with a similar study done in the Central and Sabaragamuwa Provinces [8]. Although, the above study looked at all victims of sexual abuse, irrespective of their age, 169 (60\%) of the victims were aged less than 16 years. Therefore it is possible to compare the findings with our study. This study reported that in $44 \%$ abusive incidents occurred more than once. In our study the rate was $62.9 \%$. The rate of delay in reporting to authorities was similar in both studies. Delay of more than seven days was $59.8 \%$ in our study and $52 \%$ in the other [8]. Delay in reporting resulting in delay in examination may affect the accuracy of medico-legal findings due to rapid healing. This can cause difficulty when giving evidence in courts. A study done in Anuradhapura, Ratnapura and Colombo South areas reported that the delay in reporting to authorities was low $16 \%$ [5]. The reason for early presentation in these areas is not clear but it is probably due differences in socioeconomic status and literacy rate. Our findings are similar to that reported by Vadisinghe et al regarding proportion of perpetrators known to victims (94\% vs. 96\%), situations where the boyfriend was the perpetrator (28.8\% vs. $36 \%$ ) and where a family member was the perpetrator (15.8\% vs. $21 \%)$ [8]. The place of sexual offence was the assailant's house in $30 \%$ and the victim's house in 34\%. In our study, majority of incidents took place in the offender's habitat (55.3\%).
Fathers are often named as the main perpetrators in literature but other relatives account for $20-70 \%$ of CSA occurring within the family [3]. However in our study it only accounted for $10 \%$ of the victims. Other risk factors observed were low socioeconomic status, parental separation, and prior relationship with a male, which are consistent with findings of other studies [5,7]. A high rate of single parent caregivers due to either separation, working abroad, or death was seen in our study (58.3\%). A study done in Sri Lanka reported that 34\% had a single parent caregiver [5]. Similar to a previous study, our study also found a higher female: male ratio (12:1 vs. 5:1) [5]. As these studies are based on referred cases to hospitals, it may not reflect the true picture in the community. For example, a prevalence study done among undergraduate students in the University of Kelaniya on juvenile victimization revealed that, overall $44 \%$ had experienced some form of sexual maltreatmentand $58 \%$ of the victims were male [9]. These differences may be due to under reporting of male victims to the authorities.

CSA has serious physical and psychosocial consequences. Some well-documented consequences are, post-traumatic stress disorders, depression, anxiety, deliberate self-harm, teenage pregnancy and sexually transmitted diseases [10]. In our study, acute stress reactions were reported in $11.3 \%$ and depression in $5.4 \%$. Teenage pregnancy rate was $8.3 \%$.

A unique feature of our study was, the attempt to identify risk factors for intra-familial abuse and associations with conclusive medico-legal findings. 
These were not described in other studies carried out in Sri Lanka $[5,8,9]$. Children were less likely to be willing partners in intra-familial abuse compared to extrafamilial abuse [OR=0.2; 95\% CI 0.07, 0.5). This may be because in extra-familial abuse; a non-relative was the perpetrator in the majority (47\%) and a boyfriend was the perpetrator in $28.8 \%$. These findings indicate that an unsafe home environment puts children at risk. Although we hypothesized that intra-familial abuse was associated with concealment, chronic abuse and delayed reporting, these were not higher than that in extra-familial abuse.

Diagnosing CSA is a challenge. Many children do not have physical signs even though there is a convincing history of penetrative abuse. Percentage of normal examination findings range from $6 \%$ to $99 \%$ in children referred for evaluation of sexual abuse [11]. In our study, ano-genital examination findings were inconclusive in 48 (36.3 \%). Because healing may be rapid and complete, ano-genital signs are more likely to be found when examination is done within 2 or 3 days of the abuse [12]. In contrast, this study shows that late presentation to authorities increases the odds of finding conclusive anogenital findings (OR=2.2; 95\% CI 2.0-9.4). Children who were abused chronically were more likely to have conclusive ano-genital findings (OR=4.8; 95\% CI 2.2 10.5). The positive examination findings in those who present lateto authorities may be because they are more likely to be abused many times over a period of time.

The relationship between examination findings, age and the nature of penetrating objects are unclear. In this study, a positive history given by a child ( $O R=15.3 ; 95 \%$ CI 5.6-42) and number of incidents (OR=4.8, 95\% CI 2.2-10.5) increased the odds of conclusive medico-legal findings of sexual abuse. Other factors such as pubertal status and type of hymen (fimbriated versus other types) did not have any positive association with medico-legal findings.

In conclusion, most children in this study were victims of statutory rape and majority of children knew the perpetrator. Unstable family background, poor socioeconomic status and relationships with males at a young age made children more vulnerable. A positive history of vaginal/anal penetration and number of abusive incidents were associated with positive examination findings. Further studies are needed in Sri Lanka to understand the true prevalence and complex demographic interactions, which are risk factors for abuse.

\section{Conflicts of Interests}

There are no conflicts of interest.

\section{References}

1. Finkelhor D. The international epidemiology of child sexual abuse. Child Abus Negl 1994; 18: 409-17.

2. Bachmann GA; Moeller TP; Benett. Childhood sexual abuse and the consequences in adult women. Obstet Gynecol 1988; 4: 631-42.

3. Kacker L. I, Varadan S, Kumar P. Study on Child Abuse: Ministry of Women and Child Development Government of India 2007; 44-5.

4. Sri Lanka Police. Grave Crime Abstract for the year 2015 [Internet]. Available from: http://www.police.lk/images/ others/crime_trends/2015/grave_crime_ abstract_for_the_year_2015.pdf

5. Colombage SM, Dassanayaka PB, Waidyaratna DL. A study on child abuse in Anuradhapura, Colombo South and Rathnapura. Sri Lanka J Forensic Med Sci Law 2005; 11.

6. Sri Lanka College of Paediatricians and Plan Sri Lanka. National Guideline for The Management of Child Abuse and Neglect. 2014; 15-16. Retrieved from http:// www.researchgate.net/profile/Asvini_Fernando2/publication/ 270961733_National_Guideline_for_Management_ of_Child_Abuse_and_Neglect_-_Multi_-_sectoral_Approach/ links/54bb4eb40cf29e0cb04bd90a.pdf ? inViewer=true \& disable CoverPage $=$ true $\&$ origin=publication_detail

7. Kaliray P, Drife J. Childhood sexual abuse and subsequent gynaecological conditions. The Obstetrician and Gynaecologist 2004; 209-14.

8. Vadysighe AN, Senasinghe DPP, Attygalle U, Abeysekara AMG, Gunasena MDP, Ratnayake RMUC, et al. An Analytical Study on Socio-Demographic and Medicolegal Factors of Victims of Sexual Assault from the Central and Sabaragamuwa Provinces of Sri Lanka. Sri Lanka $J$ Forensic Med Sci Law 2015; 6: 12-20.

9. Fernando AD, Karunasekera W. Juvenile victimisation in a group of young Sri Lankan adults. Ceylon Med J 2009; 54: 80-4.

10. Andrews G, Corry J, Slade T, Issakidis C, Swanston H. Child Sexual Abuse. In: Ezzati M, Lopez AD, Rodgers A, Murray CJL eds. Comparative quantification of health risks: global and regional burden of disease attributable to selected major risk factors. Geneva: World Health Organization, 2004; 1851-940.

11. Royal College of Paediatrics and Child Health. The Physical Signs of Child Sexual Abuse: an evidence-based review and guidance for best practice (2011) London: Royal College of Paediatrics and Child Health. 2011.

12. Watkeys JM, Price LD, Upton PM, Maddocks A. The timing of medical examination following an allegation of sexual abuse: is this an emergency? Arch Dis Child 2008; 93: 851-6. 